\title{
RE-MEMBER \\ Rehabilitation, Reintegration and Reconciliation of War-Affected Children
}

\author{
Ilse Derluyn, Cindy Mels, Stephan Parmentier \& Wouter Vandenhole
}

\author{
Reseña a cargo de uno de los co-editores, \\ Prof. Dra. Cindy Mels \\ Departamento de Psicología del Desarrollo y \\ Educación \\ Facultad de Psicología \\ Universidad Católica del Uruguay
}

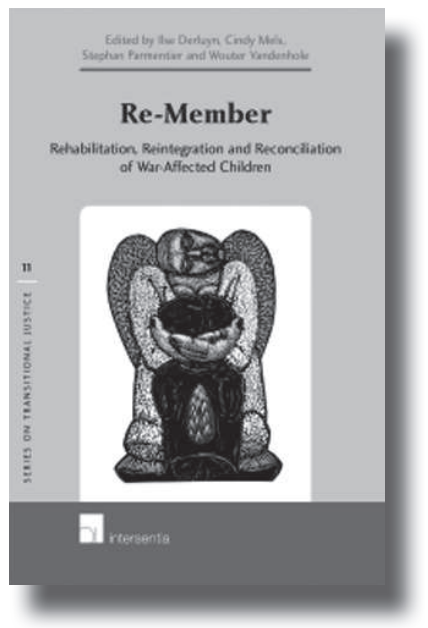

La guerra es tan antigua como la humanidad misma y siempre ha causado desestabilización, pérdidas y privaciones. Sin embargo, se ha constatado mundialmente que durante las últimas décadas la naturaleza y las tácticas de guerras han cambiado drásticamente. Consiguientemente la población civil se vio más involucrada en la reproducción de violencia - pensemos en los terroristas o los niños soldados - tanto como en sus consecuencias, causando más víctimas entre niños y mujeres que nunca antes.

Aunque no hay datos fiables sobre la cantidad de niños implicados en conflictos armados, UNICEF estimó en el año 2006 que en la década anterior, las guerras han causado la muerte de más de dos millones de niños y dejaron unos seis millones de heridos o discapacitados, unos 20 millones sin techo y más de un millón separados de sus padres. Innumerable cantidad de ellos quedaron huérfanos, sufrieron violaciones o fueron testigo de atrocidades. Incluso los niños que no están afectados de modo directo por la violencia, pueden ver perturbadas sus vidas en consecuencia de las pérdidas, la destrucción de la infraestructura local, la ruptura social, etcétera.

Queda claro que las consecuencias directas e indirectas de la guerra son extensas y profundas y afectan a varios aspectos del desarrollo humano, social e institucional. Por consiguiente, su análisis y la conjunta búsqueda de estrategias de rehabilitación y reconstrucción constituyen tanto el campo de interés de la Psicología, como la Sociología y el Derecho, entre otros. Dentro de cada una de estas disciplinas se ha desarrollado un abordaje específico de la materia, cada uno con sus propios hallazgos y méritos. No obstante, hasta recientemente el intercambio entre las distintas disciplinas que han estudiado las complejas consecuencias de la guerra e intervenciones de recuperación ha sido muy limitado, dificultando una aproximación más global del tema.

Debido a esta preocupación, se organizó en octubre 2009 en Bruselas (Bélgica) la Conferencia Internacional Interdisciplinaria sobre la Rehabilitación y Reintegración de Niños Afectados por la Guerra (International Interdisciplinary Conference on Rehabilitation and Reintegration of War-Affected Children; www.rrwac.be) invitando a académicos 
y legisladores de todas las disciplinas para presentar sus trabajos de investigación y proyectos al respecto. Sobre las bases puestas en la conferencia, en forma de contribuciones e intercambios, se redactó el presente libro.

Este libro, Re-Member. Rehabilitation, Reintegration and Reconciliation of WarAffected Children, reúne por primera vez una amplia variedad de académicos destacados de tres disciplinas (el campo de los derechos de los niños, la psicología y la justicia transicional). Aspira realizar un abordaje multidisciplinario y comprehensivo hacia la rehabilitación, reintegración y reconciliación de niños y adolescentes afectados por la guerra y los conflictos armados.

Los 22 capítulos comprenden perspectivas teóricas, hallazgos empíricos y estudios de caso, abarcando experiencias desde América Latina, África y Europa. Con su enfoque amplio - tanto en lo geográfico como lo multidisciplinario - sirve al interés de científicos, profesionales, legisladores, organizaciones no-gubernamentales y a cada ciudadano interesado, de cualquier país en el mundo.

Derluyn, I., Mels, C., Parmentier, S., \& Vandenhole, W. (2012). Re-Member. Rehabilitation, Reintegration and Reconciliation of War-affected Children. Volume 11 of the Series on Transitional Justice: Intersentia. 